\title{
Radiation Safety Program Policy Analysis
}

\author{
Laila Al Daken* \\ Teacher of Nursing, Faculty of Nursing, Zarqa University, Jordan
}

Submission: September 10, 2018 Published: September 20, 2018

*Corresponding author: Laila Al Daken, Teacher of Nursing, Faculty of Nursing, Zarqa University, Jordan, Tel: 962-5-3821100;

Email: lailadaken@hotmail.com

Abstract

This paper aims at using the incremental approach for the analysis of radiation safety program policy which is currently used in the Jordan university hospital (JUH). This policy stated that Jordan University Hospital is committed to follow ALARA (As Low as Reasonably Achievable) principle to protect staff and patients. The analysis will use a systematic method to develop alternatives and options for the identified problem in the policy statement using special criteria for the analysis. The process of policy analysis will include the following steps: establishing the context and identification of the problem, identification of policy options and alternatives, evaluate the policy options and alternatives by critically appraising pros and cons for each one, applying the scorecard table to select the suitable alternative, lastly describe the recommended solutions [1].

\section{Policy Context}

\section{Problem Identification}

Diagnostic radiology, nuclear medicine and radiation therapy have evolved in medical practices as an essential tool to help all branches and specialties of medicine. Radiation is used in health care for diagnostic and therapeutic purposes; radiation is a generic term describing a flux of elementary particles such as photons of light or electrons which include two fundamental categories: ionizing radiation and non-ionizing radiation. Ionizing radiation (e.g. X-rays and $\alpha$-particles) is sufficiently high energy particles that an electron can be removed from an atom or molecule creating an electrically charged ion pair, this ionization can damage cellular DNA and damage can lead to cell death, or to nonlethal DNA modification that can eventually lead to malignant disease (cancer). On the other hand, non-ionizing radiation does not have enough energy to break chemical bonds and produce ionization [2].

The inherent properties of ionizing radiation provide many benefits but also may cause potential harm. Ionizing radiation is one of the basic tools of contemporary medicine both in diagnosis and therapy for some diseases, exposure to ionizing radiation is known to increase the future incidence of cancer, particularly leukemia[2]. However, it is impossible to distinguish radiation-induced cancers from those that arise spontaneously. The prevalence of cancer in the U.S. population from all causes is estimated to be about $25 \%$, this means that one of every 4 people will develop a cancer at some point during their lifetime; it is thought that the total risk from radiation is accumulated from all sources of exposure including medical exposures, the occupational, medical and other exposures all add to the risk, it is estimated that an exposure of $1000 \mathrm{mrem} / \mathrm{yr}$ over lifetime may increase the risk of cancer from approximately $25 \%$ to $26 \%$ [3]. An increased number of cancer deaths can be expected during the lifetime of persons exposed to ionizing radiation. In practice of medicine there must be a judgment made concerning the benefit/ risk ratio of radiation use as well as safety program for using the radiation. Some tissues are more sensitive to the long-term effects of exposure to ionizing radiation than other [4]. There are two basic categories of the biological effects that may be observed in irradiated persons, (deterministic) or the cell killing and (stochastic or probabilistic) or the mutations which may result in cancer and hereditary effects. Effects due to mutations (such as cancer) have a probability of occurrence that increases with dose, it is currently judged that there is no threshold below which the effect will not occur and finally the severity of the effects is independent of the dose.

Thus, a cancer caused by a small amount of radiation can be just as malignant as one caused by a high dose [5]. The main protection principle in both cases is that protection should be optimized, and all doses should be kept (As Low as Reasonably Achievable), economic and social factors should be taken into account. The International Commission on Radiological Protection differentiates between three types of exposure: occupational exposure which is the exposure incurred at work and principally as a result of work; medical exposure which is principally the exposure of persons as part of their diagnosis or treatment; and public exposure which comprises all other exposures [5]. (Commission, 2013) stated that the introduction of risk mitigation procedures, such as lead aprons, increased workers and patients safety, it also suggests activities that can help eliminate, avoidable radiation doses include the following 
a) Awareness of the potential dangers from diagnostic radiation among organizational leadership, staff, and patients

b) Development of a comprehensive patient safety program, including education about dosing in imaging departments

c) Knowledge regarding typical doses

d) Adequate awareness among physicians and other clinicians about the levels of radiation typically used and related risks

e) Training in the use of complex new technology

f) Guidance in the appropriate use of potentially dangerous procedures and equipment

g) Adequately trained and competent staff

h) Knowledge regarding typical doses

i) Clear protocols that identify the maximum dose for each type of examination

j) Consulting with a qualified medical physicist when designing or altering scan protocols

k) Communication among clinicians, medical physicists, technologists, and staff

l) Safety, operational, and functional checks of the equipment before initial use and periodically thereafter.

In addition, radiation can be used as a therapeutic measure in some conditions. Patients' treatment with radiation endangers other people based on the way of administration, it can be delivered to the patient by three ways; firstly, external radiation from a radiation source outside the patient body and this type present no hazard to family or others. Secondly, Internal radiation is also called (brachytherapy) is given by placing radioactive materials implanted very close or inside the tumor either temporary or permanent and such patients present a hazard to others, they will be asked to stay in the hospital and may have to limit visitors during treatment specially pregnant women and children until their body will no longer is radioactive.

Systemic radiation in which patient maybe injected with high amount of radioactive materials, the radiation is penetrating enough to their body, patient may need to stay in the hospital for few days and health care team should tell the patient what precautions to take until their body no longer contains radiation that might affect others and visitors will be restricted from visiting the patients specially pregnant women and children [6-7]. American Cancer Society, 2014 stated that patients must follow safety precautions at least few days after the radiation treatment which include the following:

a) Flush the toilets twice after each use, and wash hands well after using the toilet.

b) Use separate utensils and towels (laundry may need to be washed separately).

c) Drink extra fluids to flush the radioactive material out of his body.

d) No kissing or sexual contact (often for at least a week).

e) Keep a distance of one arm's length between him and others who spend more than 2 hours next to him in any 24hour period. (May need to sleep alone for a week)

f) Limit contact with infants, children, and women who are pregnant.

This paper will provide analysis of the radiation safety program policy used in the Jordan University Hospital (JUH). This Hospital is an educational hospital located in Amman which have all medical sub specialties that reach about (64) different sub specialties, it provides health services for a population of approximately (572124) yearly and serving more than (25) different nationalities. JUH has a written radiation safety program policy stated that Jordan University Hospital is committed to follow ALARA (As Low as Reasonably Achievable) principle to protect staff and patients [8].

The ALARA concept is based on three general criteria:

a) Justification: the need to justify any action which involves radiation exposure.

b) optimization: to ensure that the benefits of such justifiable activities or practices is maximized.

c) Dose and risk limitation: the need to apply dose limits to ensure that individuals or groups of individuals do not exceed acceptable levels of risk.

In this policy statement, there is no inclusion of any person other than the employees and patients for example (patients' families, contractors, trainers, students, and visitors) whose health can be affected by radiation exposure; this will threaten other peoples' health with minimal responsibility of the hospital. In addition the policy does not mention any thing regarding protection programs for other radiation activities like disposal and storage. Many researchers reported that, in addition to protecting the employees, radiation program policies should be concerned with protecting all other people exposed to radiation hazards resulted from any organizational activity or service [9]. Therefore, organizations should be responsible for the safety of everyone affected by any of the organizational activities, not only the employees at workplace. Jones reported that organizations executives usually do not include visitors and other persons rather than employees in radiation safety program policies because it is difficult to be politically manageable, including only the employed persons in health policy will indirectly affect the health care delivery systems by adding economical burden on the hospital and country [10]. Therefore, this issue should be raised and moved to public agenda not only by people who are affected by hospital radiation hazards from outside the hospital, 
but also by the employees who are working at the hospital like managers, policy makers, decision makers from physician, nurses and technicians. So this paper will help in giving alternatives and options which may cover these ignored areas of practices in radiation safety program.

\section{Background}

\section{Social Context}

Careful follow-up of over 80,000 atom bomb survivors in Hiroshima and Nagasaki over the last 50 years indicates that there have been 12,000 cancer cases of which less than 700 excess deaths were due to radiation, expressed another way, only about $6 \%$ of the cancer occurring in these survivors is radiation-related these observations allow estimation of the probability with which a given dose may lead to diagnosis and death from various cancers, radiation-induced cancers do not appear immediately after radiation exposure but require time to become clinically apparent latent period. Occupational health is concerned with providing safety and prevention of all hazards in the workplace [11]. Exposures of emergency team to radiation during emergency action are likely to be higher than in normal situations. Emergencies involving significant exposures of emergency teams and should be treated as part of the occupational exposure to radiation.

\section{Ethical Context}

Since 1990 evidence has accumulated that the frequency of non-cancer diseases is increased in irradiated populations [12] and the most recent mortality analysis has strengthened the statistical evidence for an association with radiation dose - particularly for heart disease, stroke, digestive disorders and respiratory disease [13]. The ethical reasons for including people other than the staff and patients in the radiation safety policy is related to protecting those people who are vulnerable to hazards, because they are not trained to recognize these hazards as employees who are trained to make appropriate precautions. Opportunities to minimize the doses and therefore the risk from both diagnostic and therapeutic uses of radiation must be considered. This objective may be reached by avoiding unnecessary (unjustified) examinations and optimizing the applied procedures both from the standpoint of diagnostic quality and of reduction of the excessive doses to patients [14]. Several ways also should be taken in consideration for other persons who might be affected by both diagnostic and therapeutic radiations. For example, before a diagnostic procedure is performed it should be determined whether a patient is pregnant, whether the fetus is in the primary radiation area and whether the procedure is relatively high dose. For children, dose reduction is achieved by using technical factors specific for children. In diagnostic radiology careful considerations should be taken to minimize the radiation beam to only the area of interest.

\section{Legal and Political Context}

Legally, the hospital can be liable for public hazards resulted from unsafe workplace practices. Therefore, the hospital has legal responsibilities to protect the health and safety of patients' families, visitors and others affected by the organization services. From political view The International Commission on Radiological Protection (ICRP) is the primary body in protection against ionizing radiation, It provides recommendations and guidance on protection against the risks associated with ionizing radiation. This provided a significant political support for the radiation safety program policies at the regional, national and international level.

\section{Economical Context}

A commitment to an ALARA radiation safety program means making every reasonable effort to maintain exposures as far below regulatory limits as is practical. These efforts take into account the economics of improvement related to the state of technology, benefits to public health and safety, and other socio-economic considerations. Pregnant women should avoid exposure to ionizing radiation and radioactive materials as well as pregnant medical staff should avoid contact with patients being treated with radioactive isotopes. Fetal exposure to even low levels of irradiation is a risk for mental deficiency, especially when exposure occurs during the $8^{\text {th }}$ to the $15^{\text {th }}$ week of gestation. Studies also show a strong association between radiation exposure and a high risk of childhood leukemia and the development of other malignant lesions. Programs directed at informing employees of known hazards and reducing these risks by safe work practices, advice for personal protective clothing, using warning signs in X-ray areas, and a reduce the use of toxic materials. This will result in better care of pregnant workers, greater productivity by reducing the number of lost workdays and decrease financial burden to employee, employer and country [15].

\section{Stakeholders}

Stakeholders are the parties who have the stake in the outcome they could be all persons who are any of hospital managers, policy makers, and decision makers those who potentially will affect the policy or have a position on the issue or maybe any of whom are affected by radiation hazards including the hospital staff, patients, visitors, students and trainees, stakeholders can be either primary stakeholders or secondary stakeholders.

\section{Primary Stakeholders}

The primary stakeholders are the hospital managers in different levels such as the chief executive who is responsible for ensuring radiation safety programs in hospital especially for the employees, the executive director of human resources in the hospital who has the overall responsibility for ensuring that the requirements of all health policies are effectively managed, and finally all managers who are working in the hospital and responsible for ensuring their staff awareness about the policy and assist in implementation of the policy, ensure the benefits and undertake the risk of policy. Other primary stakeholders are the radiology staff whose responsibility is to implement and monitor the radiation safety program policy and provide expert advice on issues concerned with policy. 


\section{Secondary Stakeholders}

Other persons can get benefits from applying this policy are other hospital employees, families of staff, patients, visitors, students, trainers, and any of the public who can be indirectly protected from radiation hazards resulted from radiation. Also, the traders who supply the hospital with personnel protective materials will get benefits because there will be an increase of demands on these products by hospital. Finally, the government will attain benefits from this policy by increasing productivity of the workers and employees, the government also can overcome the occupational hazard cost and financial burden for the treatment of cancer disease and mutations resulted from radiation exposure.

\section{Issue Statement}

Should radiation safety program policy in Jordan University Hospital be committed to provide safety and protection from radiation hazards only to its staff and patients or it should provide safety and protection from radiation use, storage and disposal for any person affected by radiation hazards such as patients' families, contractors, visitors, students and trainers inside and outside the hospital sitting?

\section{Policy Goals and Objectives}

The main purpose of this policy is to describe the framework for the protection personnel work in the radiology and nuclear medicine department and patients undergoing medical exposures at Jordan university hospital.

\section{Policy Objectives}

a) Administrative arrangement for the radiation safety

b) Duties of the persons to such arrangements

c) Compliance to ALARA principles

d) Licensing and registration regulations according to Jordanian Atomic Energy Agency

\section{e) Put potential exposure and emergency plan}

These goals and objectives focus mainly on protecting staff and patients against radiation hazards, however, when this policy ignores other persons such as visitors, patients' families, trainers, students, and contractors, it put the safety of all these people at risk without legal accountability of the hospital. Therefore, there is a need for adding another objective regarding protecting all people in working place and other people affected by radiation activities inside and outside the hospital. As well as the policy objectives should also include the safety protection program of radiation source use storage and disposal.

\section{Policy Options and Alternatives}

Policy alternatives and options must be identified based on solutions developed and applied by other hospitals and health care sittings, or by brainstorming and discussion with experts, decision makers, policy makers and stakeholders in same health care sitting regarding new policies. The first alternative is "do nothing" or staying on the status quo option, this option will not make any modification on the current policy. This means that the radiation safety program policy will still limited to protect only staff and patients without taking in considerations other people who can be affected by radiation hazard. The second alternative is the policy stated that Jordan University Hospital is committed to follow ALARA (As Low as Reasonably Achievable) principle to protect staff, patients, patients' families, visitors, contractors, trainers and students [16]. The third alternative is the policy stated that "Jordan University Hospital is committed to follow ALARA (As Low as Reasonably Achievable) principle to ensure protection and safety of any person working in the hospital, entering the hospital, and affected by radiation inside and outside the hospital".

This is a broad option that protects people within the workplace and out of the workplace from any radiation hazard in hospital; it was adopted by [17]. The fourth alternative is the policy stated that "The radiation safety program in establishes uniform policies and procedures for the safe use of all sources of radiation within the Jordan University Hospital. This program ensures that all sources of radiation are stored, used and disposed in accordance with country and hospital regulations. It offers services to assist users or any exposed person to ensure that radiation exposure is maintained As Low as Reasonably Achievable (ALARA) within the established dose limits". This option is adopted by Stony Brook University Hospital [18].

\section{Evaluation of Policy Options and Alternatives}

Comparison of policy alternatives will be based on five criteria including effectiveness, administrative and political feasibility, cost, fairness, and social acceptability. The most important criterion is the effectiveness of policy by achieving the desired policy goals and objectives by providing protection for any person might be exposed to radiation, the political and administrative feasibility of the policy, cost of implementing alternative solutions, fairness in distribution of benefits and reducing harm and finally social acceptability among the public.

\section{Analysis and Comparison of Policy Alternatives}

\section{Alternative one}

The first alternative is the staying on the status quo or no action alternative. This option includes leaving the current policy free from any amendments to provide protection from radiation for patients and staff only.

a) Effectiveness: This option will not achieve the policy goals because the staff can be indirectly and negatively affected by applying this policy, for example radiation exposure can harm other people in hospital like patients' families, visitors, trainers, and students because they did not receive instruction about radiation precautions either inside or outside hospital sittings this put the hospital under legal 
accountability and increase the economic burden on health care system and threaten hospital staff and patients.

b) Political feasibility: It is politically feasible and manageable with less cost needed.

c) Cost: it is cost-effective from one side because it doesn't require high cost to protect patients and staff, but not cost effective from another side because may economically burden health care systems from the risk of cancer and mutations as a result of uncontrolled exposure.

d) Fairness and Social Acceptability: It is not fair because it protects the staff and patients but harm might involve other people not included in the policy. And it is not socially accepted because it did not guarantee the safety of all public in general. Therefore, it may need to be holed we might need it as a baseline to be compared with the other alternatives or options.

\section{Alternative Two}

In this alternative the policy stated that "Jordan University Hospital is committed to follow ALARA (As Low as Reasonably Achievable) principle to protect staff, patients, families, visitors, contractors, trainers and students". To achieve these standards it actively supports the principles based on recommendations of the International Commission on Radiological Protection (ICRP).

a) Effectiveness: it aims at protecting all people in hospital sitting it achieve the policy goal by protecting the staff and patients as well as it is achieve the policy goal on wider scope of people but it still limited to inside hospital.

b) Political feasibility: it is politically feasible from one side because it will include minor changes in the current policy but also not feasible from another side because it difficult to guarantee protection of all people inside hospital [19].

c) Cost: It decreases the cost and expense from radiation exposure that lead to cancer and other mutations which will outweighs the cost of applying the policy.

d) Fairness and social acceptability: It is fairer and more socially accepted than the first one because it benefits the employee, patients and all persons who entered the hospital sittings.

\section{Alternative Three}

The third alternative the policy stated that "Jordan University Hospital is committed to follow ALARA (As Low as Reasonably Achievable) principle to ensure protection and safety of any person working in the hospital, entering the hospital, and affected by radiation inside and outside the hospital".

a) Effectiveness: This option achieves benefits beyond the policy goals by include wider scope from the public so it is more effective than previous one. b) Political Feasibility: it is difficult be achieved because is not manageable and not politically feasible to protect this scope of people.

c) Cost: it is not cost-effective from one side because it needs high cost to protect all people affected by radiation but cost effective from another because may not burden health care systems from the risk of cancer and mutations as a result of uncontrolled exposure.

d) Fairness and Social Acceptability: it is fairer and more socially acceptable than previous ones.

\section{Alternative Four}

Has a wide scope of benefit which stated that "The radiation safety program in establishes uniform policies and procedures for the safe use of all sources of radiation within the Jordan University Hospital. This program ensures that all sources of radiation are stored, used and disposed in accordance with country and hospital regulations. It offers services to assist users or any exposed person to ensure that radiation exposure is maintained As Low as Reasonably Achievable (ALARA) within the established dose limits".

a) Effectiveness: This option achieves benefits beyond the policy goals by include wider scope from the public and wider scope of protection for various radiation activities, for example (radiation use, storage and disposal), so it is more effective than all other alternatives [20].

b) Political feasibility: it is difficult be achieved because is not manageable and not politically feasible.

c) Cost: it is not cost-effective from one side because it needs high cost to protect all people affected by radiation but cost effective from another because may not burden health care systems from the risk of cancer and mutations as a result of uncontrolled exposure.

d) Fairness and Social Acceptability: it is fair enough and more socially acceptable than all other options.

After generating four policy options, it is necessary to choose the best policy alternative according to the predetermined evaluation criteria. Table 1 describes and compares the policies using scorecard based on positive and negative potentials of each alternative. Although option four is politically not feasible and very costly, it is considered highly effective because it achieve goals beyond the policy goal and it has the best scores on effectiveness, fairness and social acceptability as it concerned with protection of all people from radiation use, storage and disposal, it has also a total score of 7 , which is the highest overall score among all other alternatives. Option three is effective, fair and socially accepted but has lower total score than option four, option two has positive for all criteria but still also has lower total score than option three and four. Lastly, option one has zero total score and it is not effective, not fair, not socially acceptable. 


\section{Comparison of Alternatives by Scorecard}

Table 1.

Table 1: Comparison of policy alternatives for radiation safety program.

\begin{tabular}{|c|c|c|c|c|}
\hline & \multicolumn{4}{|c|}{ Alternatives } \\
\hline & Option1 & Option2 & Option3 & Option4 \\
\hline Criteria & & & & \\
\hline Effectiveness & - & + & ++ & +++ \\
\hline Political Feasibility & +++ & $+/-$ & - & -- \\
\hline Cost & $+/-$ & + & $+/-$ & $+/-$ \\
\hline Fairness & - & + & ++ & +++ \\
\hline Social acceptability & - & + & ++ & +++ \\
\hline & -1 & -5 & -3.5 & -3.33333 \\
\hline Total & 0 & 4 & 5 & 7 \\
\hline
\end{tabular}

\section{Recommended Solution(s)}

Based on this analysis option four is considered the recommended solution for the identified problem. This analysis is based on incremental approach, so it needs to be modified to a new policy which stated "The radiation safety program in establishes uniform policies and procedures for the safe use of all sources of radiation within the Jordan University Hospital. This program ensures that all sources of radiation are stored, used and disposed in accordance with country and hospital regulations. It offers services to assist users and all exposed persons to ensure that radiation exposure is maintained As Low as Reasonably Achievable (ALARA) within the established dose limits". There is a need to add another policy objective which is protecting all people exposed to radiation in hospital and outside hospital from different radiation uses, storage and disposal. Moreover, one important objective is to ensure that any person enter the hospital whether employed or not, should receive instructions by healthcare providers to reinforce the radiation safety program. The recommended instruction should be consistent with the recommendations of the International commission on radiological protection (ICRP), this adds political support for the policy as well as social support by the government, employees, and the general citizens because it is economical, directed toward their benefit and can decrease the cost of absenteeism due to less exposure to occupational hazards [21]. Therefore, the new policy will be supported by a wide range of stakeholders who will raise the issue to be adopted and abided by.

\section{References}

1. Mason D, Leavitt J, Chaffee M (2007) Policy and politics in nursing and health care. Saunders, Philadelphia PA, USA.
2. Cosset J, Liniecki, Ortiz Lopez, Ringertz, Sharp, et al. (2004) Radiation and Your Patient: A Guide for Medical Practitioners.

3. Wiebeck K (2009) Nursing Procedures for Radiation Therapy Patients, Radiation Safety Officer. pp. 686-7803.

4. Protection I.C.O.R (1991) ICRP Publication 60: 1990 Recommendations of the International Commission on Radiological Protection: Elsevier Health Sciences.

5. Lindell, Dunster, Valentin J (1998) International Commission on Radiological Protection: History, Policies, Procedures. Swedish Radiation Protection Institute, SE-171,16, p. 1-12.

6. Sisson, Freisatas J, McDougall, Dauer, Hurley, et al. (2011) Radiation safety in the treatment of patients with thyroid diseases by radioiodine 131I: practice recommendations of the American Thyroid Association. Thyroid 21(4): 335-346.

7. American Cancer Society (2014) Understanding radiation therapy: A guide for patients and families.

8. Al Sharif, Abu EL Sheikh (2013) Radiation Safety Manual. Jordan University Hospital, Jordan.

9. Agbol (2012) Impact of Health and Safety Management on Employee Safety at the Ghana Ports and Harbour Authority. Developing Country Studies 2(9): 156-166.

10. Jones G (2007) The visitor's safety policy, Why You Need One \& How to Create It.

11. WHO (2006) Health effects of the Chernobyl accident and special health care programmes.

12. Valentin J (2007) The 2007 recommendations of the international commission on radiological protection: Elsevier Oxford.

13. Picano E (2005) Economic and biological costs of cardiac imaging. Cardiovascular Ultrasound 3(1): 13.

14. Commission J (2012) Improving Patient and Worker Safety: Opportunities for Synergy, Collaboration and Innovation. The Joint Commission, Oakbrook Terrace, IL, USA, pp. 1-162.

15. Feinberg J, Kelley (1998) Pregnant workers. A physician's guide to assessing safe employment. Western journal of medicine 168(2): 8692.

16. (2014) Radiation safety manual for mercy hospital Dunedin.

17. (2009) Radiation safety program. Maissouri state university.

18. (2015) Stony Brook University Hospital Environmental Health \& Safety Policy \& Procedure Manual.

19. Wakeford R (2004) The cancer epidemiology of radiation. Oncogene 23(38): 6404-6428.

20. World Health Organization (2013) Occupational health.

21.X- Ray safety manual (2013) A manual of guidance, policies and procedures specific to the use of x-rays in Diagnostic Imaging, Winnipeg Regional Health Authority. WRHA X-ray Safety Committee. 
This work is licensed under Creative Commons Attribution 4.0 License

DOI: 10.19080/JOJNHC.2018.09.555768

\section{Your next submission with Juniper Publishers will reach you the below assets}

- Quality Editorial service

- Swift Peer Review

- Reprints availability

- E-prints Service

- Manuscript Podcast for convenient understanding

- Global attainment for your research

- Manuscript accessibility in different formats

( Pdf, E-pub, Full Text, Audio)

- Unceasing customer service

Track the below URL for one-step submission https://juniperpublishers.com/online-submission.php 